\title{
A META-ANALYTIC ANSWER TO AN OLD DILEMMA: DO M\&AS CREATE VALUE? \\ EVIDENCE FROM EUROPEAN BANKS
}

\author{
Federica Angeli \\ Department of Management \\ University of Bologna \\ Via Terracini, 28 \\ 40131 Bologna - Italy \\ Phone: +390512090337 \\ Fax: +390512090222 \\ E-mail:f.angeli@unibo.it \\ Enrica Bolognesi \\ Department of Management, \\ University of Bologna \\ Via Capo di Lucca, 34 \\ 40126 Bologna - Italy \\ Phone: +39-051-2098073 \\ Fax: +39-051-2093946. \\ E-mail: enrica.bolognesi@unibo.it \\ Laura Toschi \\ Department of Management, \\ University of Bologna \\ Via Capo di Lucca, 34 \\ 40126 Bologna - Italy \\ Phone: +39-051-2098073 \\ Fax: +39-051-2093946. \\ E-mail: laura.toschi@unibo.it
}

\begin{abstract}
This paper aims at shedding further light on the controversial impact of M\&As on the value creation perceived by investors, as the short-term market performance of the firms involved. 17 event studies are examined by following a meta-analytical procedure. The unit of analysis is originally assumed as the event window within each study, yielding a total sample of 191 observations and 17,007 deals. Separate analyses are run for bidders, targets and combined entities. Our findings highlight the insensitiveness of bidders to M\&As' announcement, in line with existing theory. Interestingly, the choice of the benchmark in the market model, the geographical scope and the event window position prove to be significant moderators: Italian M\&As are less profitable than European ones, and preannouncement rumours significantly alter the overall performance.
\end{abstract}

Key-words: M\&A, European banks, Meta-analysis, Event studies 


\section{INTRODUCTION}

Mergers and Acquisitions (M\&As) have gained increasing popularity as strategies to achieve corporate growth and diversification. Indeed, the last decade has witnessed smashing records, both in terms of the number of transactions and the size of deals (Thomson Financial Service 2001), with an impressive consolidation dynamic in the European financial sector, as can be observed in Table 1.

Insert Table 1 about here

However, academic research has been highlighting a much less enthusiastic portray of M\&As' performance. Investigation so far failed to achieve convincing findings explaining the variance in postacquisition results (Hitt et al. 1998; Hoskisson et al. 1994; Sirower 1997) and since 1988 a question has been carving scholars' mind: 'Why do acquiring-firm managers enter so readily into the market for corporate control, given its well-known large risks and apparently modest returns?' (Magenheim and Mueller 1988; Walker 2000).

Whereas research has broadly underlined that M\&As' target firms typically enjoy positive returns, a rich bunch of studies firmly supports bidder firms' stockholders' loss after the M\&A announcement in the long run (Agrawal et al. 1992; Louis 2004; André et al. 2004). This can basically be explained by the bidding process leading to an acquisition. The premium price paid by the acquiring firm typically exceeds the current market value of targets, thus engendering high merger costs for bidders and strong rise in target's stock market returns. Roll (1986) discusses the fact that bidders are usually overpaying their targets. Considering the cases in which a rival bidder exists, the bidding competition between the two will stop when the winner offers a price that overestimates the target firm, even though management might still believe in the opportunity to extract synergies and to improve efficiency. The bidder overestimates the value of the potential synergies and, thus, pays too much, entailing a negative impact on their stock market returns. 
Giving a glance to the literature as a whole, a strong heterogeneity in bidders stock market returns emerges and the negative sign of the effect failed to achieve a robust empirical test. A set of recent works highlights mixed results, both in the sign of the relationship and in the variance. A flourish range of variables alleged to explain the performance variance is thus proposed: strategic focus (Healy et al. 1992; Megginson et al. 2004), book-to-market ratio (Rau and Vermaelen 1998), method of payment (e.g. Walker 2000), hostility of the transaction (Loughran and Vijh 1997), to cite a few.

A further stream of M\&A literature thus tries to investigate the importance of 'softer' variables in capturing the variance of bidders' shareholders gain. These studies, focusing on the comparison between the two merging companies, addressed the role of the cultural fit (Cartwright and Cooper, 1996; Schweiger and Goulet, 2000), management style similarity (Datta 1991; Larsson and Filkelstein 1999), inter-firm learning through knowledge transfer (Ahuja and Katila 2001; Bjorkman et al. 2003; Singh and Zollo 2004; De Vincenzo et al. 2006) and resource sharing (Capron and Pistre 2002).

Summarizing, the overall portray of bidder post-acquisition performance appears to be confused. Thereby, the disentanglement between enthusiast managerial practice and much more doubtful and inconclusive empirical results sounds paradoxical and a deeper investigation of the phenomenon is required.

Diaz et al. (2004) show a list of value-maximizing reasons that can explain the consolidation of the banking sector: scale economies, scope economies, market power, improvement of management efficiency, decrease of risk through geographic and product diversification. Nevertheless, the authors acknowledge that M\&As may sometimes occur even without any positive NPV; such deals are thus undertaken without any measurable, economical benefit. Some 'non value-maximizing' motives are thus supposed to underlie these non-value creating deals.

Considering previous studies' results, many scholars conclude that managers seek to maximize firm size (size-maximizing hypothesis), rather than shareholders' wealth (Walker, 2000). Indeed, 
managers often pursue objectives different than shareholders, since the former benefit from increasing firm size in terms of higher salaries and higher perceived professional status. Managers are thus tempted to acquire other companies just to faster reach larger size, as the well-known agency problem highlights (Berger et al. 1999).

In this scenario, meta-analytical approach gains multi-fold relevance. Meta-analysis is a statistical technique which, while correcting for various statistical artifacts, allows for the aggregation of results across different studies to obtain an estimate of the true relationship between two variables in the population. Through meta-analysis, both the direction of the effect and its magnitude can be tested across studies; moreover, characteristics of the studies can be highlighted and tested, in order to explain some variance in the results, which might depend on the single study measurement choices rather than on exogenous factors. A previous meta-analysis by King et al. (2004) highlights the presence of unidentified moderating factors and fosters future research to explore further. Thus, we try to identify possible characteristics of the studies moderating the relationship between M\&A event and short-term performance, hopefully capturing some of the variance of results.

We chose to limit our study to Europe. EU represents a fertile empirical setting where to investigate further the phenomenon and to either support or confute previous meta-analyses and similar studies (King et al. 2004). Heterogeneity among EU member states implies high levels of diversification pursued through cross-boarder mergers but, on the other hand, the difficult exploitation of synergies and knowledge transfer. In this framework it is interesting to verify whether the peculiarities of a specific European country's banking system can affect the investors' reaction to the deal. For this reason, we give special emphasis to the Italian context as opposed to European as a whole. Italian banking consolidation process has been playing a leading role in the general European trend over the past 20 years and has lately attracted the attention of many researchers. 
We focus our analysis on the short-term market performance of the firms' stock involved in a M\&A deal, in order to catch the market reaction of the financial community to the "new event". As far as stock market returns represent the perceived and expected efficiency improvement, this measure is useful to determine whether financial markets believe or not in the managerial strategy.

Meta-analysis requires that findings must be both conceptually comparable and configured in statistically equivalent forms (Lipsey and Wilson 2001; Ellis 2006). Hence, we chose to focus on event studies, which link the M\&A announcement to company's short-term CARs (Cumulative Abnormal Returns) through a fairly comparable statistical model. These studies are assuming that stock prices are simply the present value of expected shareholders' future cash flows: since 1970s this perspective has strongly dominated the measurement of M\&A profitability (Bruner 2002). Considering that the methodology underling event studies provides some degree of freedom to the researcher in building up his/her measures, we analyse some of the measurement features which might affect either the sign or magnitude of the achieved results. In particular, the choice of a distinctive benchmark in the CARs estimation and the selection of different event window's lengths and positions lead to dissimilar model specifications that can explain part of the variation of the results across studies.

Thus, our research questions would sound as follows: is the stock market reaction to M\&As' announcements generalizable across studies? Is this affected by measurement issues? And finally, is the Italian focus of the deal likely to affect the M\&A short-term performance?

\section{METHODS}

\section{Sample}

In order to analyse the effect of the consolidation process in the European bank industry, we underwent a research of related articles published in the major international journals of management, economics, finance or banking. This process started with a computer search browsing several 
databases: JSTOR, ProQuest, Google Scholar, Ssrn and Findarticles. The keywords included are a combination of the following terms: merger, acquisition, M\&A, Europe, European, bank, banking, consolidation, value, efficiency and performance. The search process yielded a total of 121 articles or working papers, mainly addressing US M\&A transactions/deals. Additional studies published in books or other journals were identified through the so-called "snowball technique", which leverages on the references provided by previously identified papers to highlight some more relevant works.

We then created our final sample by following three eligibility criteria. First, studies were included only if their focus was on the European bank industry as a whole area, or concentrated on a single European Country (Italy, Portugal, Norway and Greece). Second, articles based on qualitative results and reviews were excluded from the sample. Finally, we restricted our analysis to studies deploying an event study methodology. This responds to a precise requirement when running a metaanalysis: the model to be tested, along with the measures used to operationalize the constructs must be homogeneous, in order to allow for a robust comparison across different studies. Event studies rely on a model based on daily prices, which is widely recognized as the most suitable proxy to observe the presence of Abnormal Returns (ARs) of the stock under investigation. This means event studies ensure a high level of methodological homogeneity that can lead to an easy and reliable comparison of the results, thus reducing the file-drawer problem (Shapiro and Shapiro 1982; Rosenthal 1991). Moreover, event studies make use of large samples, which allow the researcher to avoid considering to reduce the presence of sampling error, and to by-pass the micro-peculiarities of the firms involved. Event studies thus perfectly match our main meta-analytical purpose, which aims at observing the relationship between variables and at testing theories through the accumulation of knowledge across studies.

Our final sample is composed by 17 empirical studies corresponding to 931 European M\&A deals and reflecting a total sample size of 17,007. As the actors involved in merge and acquisitions transactions are the bidders, the targets and the two companies as "combined" entities, we performed 
three different meta-analyses to separately understand the effect of the M\&A deal on their short-term stock market returns. It is important to note that the decision to focus our attention also on the combined entity is driven by the need to capture the value creation on a net and aggregate basis rather than looking only at targets and bidders separately.

\section{Unit of analysis}

In order to provide current scholar debate on M\&A success with some relevant scientific contribution, some specifications are needed, particularly referring to the unit of analysis and to the variables we are testing. Event studies base their evidence on event windows which can differ in terms of lengths and positions with respect to the event chronological collocation. The most typical event study runs analyses on increasing larger windows across the M\&A's announcement date. Thus, from a meta-analytical standpoint, the single study actually provides us with multiple meta-analytical observations, equal to the number of time windows the single study is testing. Furthermore, separate analyses are typically run for target firms, bidder firms and the two combined companies. For this reason, our unit of analysis became the event window of each study, instead of the single study. Following this method, the size of our final sample soars from 17 to 190 units.

As far as the model we are going to test across studies is concerned, our independent variable is the M\&A event. Though some authors explicitly distinguish merger events from acquisition events (Tourani Rad and Van Beek 1999), the broad majority of studies treat merger and acquisitions as some undifferentiated phenomenon. In the purpose of our meta-analysis, we adopt the common view and we chose not to catch the nuances distinguishing the two kinds of events. More in general, we considered as the distinctive feature of such operations the change in the ownership structure of acquired firms, with the shift of control from the targets' shareholders to the bidders' ones. According to the most typical practice of event studies, the dependent variable of the model we are testing is the CARs of 
target, bidder and the deal (combined entity), measured on windows of different length and positions with respect to the M\&A's announcement date.

The added-value of our meta-analysis first lays in the possibility to test the direction of causality and the magnitude of the relation linking the M\&A announcement to its stock market reaction (the CARs). Second, we identify possible characteristics of the studies moderating the relationship under exam and hopefully explaining some of the variance of results. We will address the first issue and then focus on the research of moderators in the following section.

\section{Effect Size}

The first step of the meta-analysis is the estimation, for each study, of a common effect size measure in order to aggregate and compare empirical findings drawn from different researches and to establish a strong empirical generalization, increasing the explanatory power and reducing the type II errors (i.e. the error of failing to reject a null hypothesis when the alternative hypothesis is the true state of nature). In order to perform this first step of the meta-analytical procedure, we rely on the Pearson product-moment correlation coefficient $r$, which is most widely used and is in line with the guidelines provided by Hunter and Schmidt (1990). Furthermore, to interpret the significance of mean effect sizes we refer to Lipsey and Wilson (2001), using confidence intervals. Indeed, a confidence interval at the 95\% significance level and excluding 0 allows to assert that the mean effect size is statistically significant at the $5 \%$ level. The difference between this procedure and the standard significance test is that the confidence intervals are centered on observed values rather than on the hypothetical value of a null hypothesis (Hunter and Schmidt 1990).

\section{Sampling Error}


The simple zero-order correlation calculated in the first step of the meta-analytic procedure is not the best measure of the effect size. Indeed, as study validity will vary randomly according to different sample sizes, because of sampling error, the aim of the second step is the correction for this "artifact". This measure of corrected effect size is assessed by weighting each correlation coefficient $r$ for its sample size, here measured by the number of targets, bidders and combined entities in each event window of the single study. In a next step, we compute, for each meta-analysis, the variance of the observed effect size $\left(\sigma_{r}^{2}\right)$, of the sampling error $\left(\sigma_{e}^{2}\right)$ and the residual variance obtained by subtracting $\sigma_{e}^{2}$ from $\sigma_{r}^{2}$, in order to test for the presence of moderators which might affect the magnitude of the M\&A-value creation link. The aim of this last step is to understand to which extent some variance (i.e. heterogeneity) is captured by sampling error, and to which extent it can be due to specific characteristics of the studies included in our sample.

\section{Moderators}

We are now trying to understand whether some peculiarities of the studies we surveyed might be affecting the magnitude of such causal relation. Thus, we try to highlight some elements with moderation power, which we can define as qualitative or quantitative variable that affects the direction and/or strength of the relation between an independent or predictor variable and a dependent or criterion variable (Baron and Kenny 1986). Assmus et al. (1984) summarize the characteristics of different studies by distinguishing two groups: 1) those related to model specification, measurement and estimation and 2) those related to specifics of the research environment in a particular study.

In the case of measurement features, event study methodology allows the researcher to make some important choices concerning the parameters' estimation. In particular, we are interested in the choice of the benchmark to be fitted in the regression model: the researcher can select either a country stock market index, representing the general market performance of the firm's geographic area, or a sector 
market index, that is composed only by the main stocks of the same company's industry. The entity of the differences in CARs, calculated using the two indexes, can be quite relevant. If a disparity in ARs on a firm's stocks does exist, we expect it to be greater when adopting the country market index rather than the sector market index. The reason holds mainly on two basic considerations. First, a firm's stock usually shows different weights inside the two indexes (the market indexes' constituents are usually weighted on a market-cap criteria). For example, if a large cap stock is a constituent of the index representing its country stock market exchange, it will definitely be a component of its industry market index but with a higher weight. As a consequence, the deal announcement will also have a stronger influence on the sector market index than on the country market index. The second reason relies on the widespread effect of a deal announcement within its own sector. In particular, whenever an acquisition is publicly announced, a reaction can be registered at the industry group level. It is reasonable to expect that a stronger investors' sentiment on a sector consolidation could induce themselves to recognize a market premium to other firms of the same industry group even if not directly involved in the deal. In practice, the research of good investment opportunities inside the sector becomes a general theme of investment. These two contrasting effects can lead to an alteration of the correlation coefficient calculated taking into account the stock's market performance of the firm involved in the M\&A and the performance of its entire sector.

We also highlight the importance of the position of the event window with respect to the announcement date in investigating post-acquisition performance as a determinant feature of the model specification. We distinguish the event windows observed in the studies into three groups: post, pre and around the event. In particular, due to financial markets' imperfections as well as possible preannouncement information spill-overs, we argue stronger returns to occur in the pre-announcement event window rather than in the post- and around-announcement cases. Thus, the variance in CARs is 
supposed to be partially explained by the event window position with respect to the announcement date rather than by the window length.

If we focus on the contextual factors explaining the variation of the results across studies, we decide to consider Italy-focused studies versus Europe-focused studies for two main reasons. The first relates to the prominence of the Italian banking consolidation process over the past 20 years, as can be observed in Table 2. The second reason concerns some peculiarities of Italian deals within the banking sector such as the preponderance of friendly agreements over hostile takeovers.

Insert Table 2 about here

\section{RESULTS}

\section{Overall findings}

The purpose for meta-analysis is to estimate the relationship that would have been observed if studies were conducted perfectly. Considering the event window $j$ of the study $i$ (instead of the single study $i$ ) as our unit of analysis, in Table 3 we show the observed and corrected correlations for the entire sample of each meta-analysis. These data are aggregate values explaining the relationships between the announcement of an M\&A and the final CARs for targets, bidders and combined entities.

\section{Insert Table 3 about here}

Observing the results, it is straightforward to observe how the correction for the sampling error plays an important role. Indeed, the coefficients $r$ are significantly different before and after the correction. This means that avoiding correcting the $r$ by weighting it for its sample size could lead to a relevant overestimation of the magnitude of the relationship under exam. The corrected $r$ for targets and combined entities is equal to 0.570 and 0.402 respectively $(\mathrm{CI}=0.570-0.571$ for target and $\mathrm{CI}=$ 
0.402-0.403 for combined entities). In line with extant literature, these findings confirm that M\&A announcements positively affect targets' stock market returns, generating also short term shareholders' wealth for combined financial entities, but with minor impact. We also resolve the dilemma around the value creation for bidders: the $r$ mean obtained, after the correction for sampling error, is greater than the observed value (before the correction), but substantially lower if compared to the target's and combined entity's values $(r=0.045$ and $\mathrm{CI}=0.045-0.045)$. This finding suggests that financial markets do not recognize, on average, a value creation of the deal to the bidders. This is in accordance with the previous literature highlighting that buyer's ARs deriving from M\&A activity are essentially zero (Bruner, 2002).

Furthermore, the $Q$-statistic captures the extent of variance in the dispersion of effect sizes around the mean. Q values higher than the critical point for a given significance level $(\alpha=5 \%)$ enable us to reject the null hypothesis of homogeneity (Cochran, 1954). In these cases, indeed, the variance within the sample is not completely explained by the sampling error and the residual variance is due to the presence of other variables affecting the M\&A-value creation relationship. In our analyses, the $Q$ statistic for targets is equal to 586.299 and greater than 85.965 of (with probability $5 \%$ and 66 degrees of freedom), confirming the necessity to look for potential moderator variables. Analogous results are also achieved for bidders $(149.885>104.139)$ and combined entities $(170.705>55.758)$. In the next section, we will address this issue, investigating which and how moderators influence our main relationship.

\section{Moderators}

As previously pointed out, we found, for all the three meta-analyses, the presence of heterogeneity not explained by sampling error. To determine whether this heterogeneity can be explained by some moderating variables, we performed a $\mathrm{Q}$ test analysis splitting the sample into 
subgroups on the basis of the moderators identified. We then compare the mean effect sizes and the corresponding confidence intervals between groups. In order to test for the significance of the differences among the means of the subgroups, we consider the confidence intervals. This is in line with the previous methodology used to test the significance of the effect size. Furthermore, this analysis is performed only on a restricted sample for two main reasons: first, we excluded all those observations having missing data for some of the moderators. Second, for the "event window" moderator, we focused only on the observations referred to the pre- or between- event windows, as most of the post- event windows of our original sample considers periods which are far from the event under analysis and could not capture the short-term market performance of the firms.

We focus on two common moderators generally considered in meta-analytic researches: measurement factors and contextual factors (Brown et al. 1998). The moderators belonging to the first group are the stock market index (used as benchmark in the market model) and the CARs' event windows. The contextual factor, instead, aims to show differences among the countries in which the M\&As occurs: we select Italy as our benchmark and we compare the peculiarities of the Italian banking system with the broader group of the European banks. After classifying the data into subsets according to these moderator variables, we test the presence of heterogeneity across and within our studies.

The results of the moderator analysis are summarized in Table 4, where it is highlighted the importance of these three factors. The between-group homogeneity $\left(\mathrm{Q}_{\mathrm{B}}\right)$ is always significant at the 5\% level. This means that the differences in average between the split groups always matter, extending the results derived by the simple sampling error analysis. However, also the within-group Q statistic $\left(\mathrm{Q}_{\mathrm{W}}\right)$ results appears to be significant, suggesting that the variation within the distribution of $r$ is not completely resolved. This implies that the identified moderators are not sufficient to explain all the variance observed in the sample and that further moderators are necessary to make the subsets homogeneous. The next sections are aimed at analyzing the effect of moderators in deeper detail. 
Insert Table 4 about here

\section{Measurement Moderators}

Benchmark Index. The first moderating factor under observation is the choice of the benchmark index. Our results show that the use of country market index as a benchmark positively affects ARs for target $(r=0.7$, with $\mathrm{CI}=0.699-0.700$, for the market index is greater than $\mathrm{r}=0.484$, with $\mathrm{CI}=0.483$ 0.484, for the sector index) and bidder $(r=0.075$, with $\mathrm{CI}=0.075-0.075$, for the market index is greater than $r=-0.043$, with $\mathrm{CI}=-0.043--0.042$, for the sector index). These findings suggest that the choice of the sector market index as a benchmark leads to the underestimation of the deal announcement's effect on the companies' stock market prices.

CARs' Event Window. We then highlight the importance of the position of the event window in investigating post-acquisition performance. Event study methodology takes into consideration several event windows: post, pre and around the event. Our results show that pre-announcement event windows show higher stock market returns than post or between announcement event windows for targets and combined $(r=0.894$ and $\mathrm{CI}=0.893-0.895$ for target; $\mathrm{r}=0.501$ and $\mathrm{CI}=0.500-0.501$ for combined), and lower stock market returns for bidders $(r=0.025$ and $\mathrm{CI}=0.024-0.027)$. These results are in line with hypotheses of financial markets' imperfections as well as possible pre-announcement information spill-overs, that imply stronger returns to occur in the pre-announcement event window rather than in the post- and around-announcement cases. Jensen and Ruback (1983) find that in the case of successful merger, almost half of the targets' ARs associated with the merger announcement occur prior to their public announcement. 


\section{Contextual Moderators}

Italy vs. Europe. Considering Italy-focused studies versus Europe-focused studies, we find that Italian M\&As entail lower stock market returns than European M\&As in all the meta-analyses. Indeed, the value of the corrected $r$ for the European deals is always greater than for the Italian ones $(0.583>$ 0.400 and $\mathrm{CI}=0.583-0.584$ for target, $0.023>-0.134$ and $\mathrm{CI}=0.023-0.023$ for bidder, $0.454>-0.082$ and $\mathrm{CI}=0.454-0.455$ for combined). A strong argument can explain this result: Italian M\&As are typically friendly takeovers, and the conditions are previously agreed. This means that the market for corporate control does not have an important relevance and hostile takeovers are rare (Melis 2000). The direct consequence of friendly takeovers is that targets' value does not benefit from the progressive increase due to the effect of price race. Regarding the bidder entities, an important aspect to be highlighted relies on the main driving forces behind Italian banks takeovers. De Vincenzo et al. (2006), in an empirical study of Italian bank acquisitions between 1995 and 1999, explain the poor results of Italian M\&As with agency-related issues rather than efficiency motivation. Furthermore, Resti and Galbiati (2004) point out the lower performance obtained by Italian bidders is attributable to a scarce investor relation efficacy to highlight the benefits deriving from the deal.

\section{CONCLUSIONS AND FUTURE RESEARCH}

Acknowledging the richness of literature which aims to understand the presence of value creation on M\&A deals, we attempted to verify some of the results from a meta-analytical standpoint. Firstly, we confirm that acquiring firms do not receive any net benefit from M\&A looking at the short term market returns. In other words, acquisitions seem to offer zero NPV to the shareholders and then buyers essentially appear to stare at the break even of their investments. A frank question thus arises: do M\&As create value? And, if the stock market prices reflect the financial analyst's future expectations of a firm, why the financial community does not recognize any advantage for buyers from 
an industry consolidation deal? The initial paradoxical dilemma seems to achieve something similar to an answer: investors consider M\&As as driven by non-profit-maximizing motivations, namely by agency related needs, such as empire-building strategies; they thus fail to recognize value to these transactions. This has been broadly explained by means of the agency theory, which supports the disentanglement between managers' and owners' objectives. If bidders' stock market value remains unaltered, the final impulse to consolidation recognized by investors must lay somewhere else. The need to increase market share through an external growth and to achieve a bigger size is to be considered as the most feasible driver, in most cases achieved by overpaying the target firm.

A second interesting finding can be highlighted. Geographical area significantly moderates the main relationship, thus affecting stock market returns: our evidence suggests Italian deals are perceived to be less profitable than European ones. This finding triggers interesting theoretical speculation and originally adds on extant literature. Italian practice typically relies on friendly takeovers and previous inter-partner agreements, thus avoiding bidding up process. This clearly hinders the effect of M\&A deals on target performance. However, this result is in contrast with the idea of higher prices paid for the control of Italian banks, characterized by unclear and inefficient ownership's structures (Resti and Galbiati 2004). On the bidders' side, buyers seem unable to take advantage from the absence of a competitive bidding up process, showing lower market performances than European ones. This finding suggests that investors perceive efficiency related motivations to have even poorer influence on Italian M\&As' deals than European ones.

As far as methodological implications are concerned, our study underlines the significant difference in estimating CARs on event windows previous to the deal announcement rather than in post or in between time periods. This finding proves the presence and the strong effect of pre-announcement market rumours in estimating M\&As' performance, thus confirming markets' imperfect efficiency in spreading information. Furthermore, there seems to be significant difference in considering country 
market index, inside the market model, as opposed to sector index, in estimating targets' and bidders' CARs. This can provide future research, with strong evidence of the underestimation effect of the use of sector index rather than country market index.

This papers aims at nurturing future research with some fertile inputs. First of all, we chose to restrict to event studies, in order to strictly portray short-term effect, mirroring financial analysts' perceived, expected value of the deal. Future studies might consider to include the consistent body of literature enquiring post-acquisition performance by means of accounting-based measure. It would be interesting to compare the perceived value embedded in ARs in short-term time horizon with actual synergies generated by the deal in medium/long-term perspective. In particular, the study could cope with extreme heterogeneity of accounting-based measures by correcting for what Hunter and Schmidt call restricted sampling error. Every accounting measure could be supposed to measure some inbetween segment of the ideal continuum. 


\section{REFERENCES}

*Study included in the meta-analysis.

Agrawal, A., Jaffe, J., Mandelker, G. (1992). The post-merger performance of acquiring firms: a reexamination of an anomaly. Journal of Finance, 47(4), 1605-1621.

Ahuja, G., Katila, R. (2001). Technological Acquisitions and the innovation performance of acquiring firms: a longitudinal study. Strategic Management Journal, 22(3), 197-220.

Andrè, P., Kooli, M., L'Her, J. (2004). The Long-Run Performance of Mergers and Acquisitions: evidence from the Canadian Stock market. Financial Management, 33(4), 27-43.

Assmus, G., Farley, J.U., Lehmann, D.R. (1984). How advertising affects sales: Meta-analysis of econometric results. Journal of Marketing Research, 21(1), 65-74.

Baron, R.M., Kenny, D.A. (1986). The moderator-mediator variable distinction in social psychological research: Conceptual, strategic, and statistical considerations. Journal of Personality and Social Psychology, 51(6), 1173-1182.

*Beitel, P., Schiereck, D. (2001). Value creation at the ongoing consolidation of the European banking market. Paper presented at the X International Conference on banking and finance in Rome, 5-7 December.

Berger, A.N., Demsetz, R.S., Strahan, P.E. (1999). The consolidation of the financial services industry: Causes, consequences, and implications for the future. Journal of Banking \& Finance, 23(2), $135-194$.

Bjorkman, I., Tienari, J., Vaara, E. (2003). Trapped in the past or making use of experience? On learning in post-merger integration. In Soderberg, A.M. and Vaara, E. Merging across borders. Copenhagen: Copenhagen Business School Press.

Brown, S.P., Homer, P.M., Inman, J.J. (1998). A meta-analysis of relationships between ad-evoked feelings and advertising responses. Journal of Marketing Research, 35(1), 114-126.

Bruner, R. (2002). Does M\&A Pay? A Survey of Evidence for the Decision-Maker. Journal of Applied Finance, 12(1), 48-68.

*Campa, J.M., Hernando, I. (2006). M\&A performance in the European financial industry, Journal of Banking and Finance, 30(12), 3367-3392.

Capron, L., Pistre, N. (2002). When do acquirers earn abnormal returns?. Strategic Management Journal, 23(9), 781-794. 
Cartwright, S., Cooper, C.L. (1996). Managing Mergers, acquisitions and strategic alliances: integrating people and cultures. Oxford, Butterwooth \& Heinemann.

*Caruso, A., Palmucci, F. (2005). Measuring value creation in bank merger and acquisitions, WPS.

*Chen, Z., Li, D., Moshirian, F., Tan, J. (2005). Does Bancassurance Add Value to Banks? Evidence from. Mergers and Acquisitions between European Banks and Insurance Companies. WPS.

Cochran, W.G. (1954). The combination of estimates from different experiments. Biometrics, 10(1), $101-129$.

*Cybo-Ottone, A., Murgia, M. (2000). Mergers and shareholder wealth in European banking. Journal of Banking and Finance, 24(6), 831-859.

Datta, D.K. (1991). Organizational fit and acquisition performance: Effects of post-acquisition integration. Strategic Management Journal, 12(4), 281-297.

*Davidson, I., Ismail, A. (2005). Further analysis of mergers and shareholder wealth effects in European banking. Applied Financial Economics, 15(1), 13-30.

De Vincenzo, A., Doria, C., Salleo, C. (2006). Efficiency vs. agency motivations for bank takeovers: some empirical evidence. Temi di discussione del Servizio Studi Banca d'Italia.

*DeLong, G.L. (2003). The announcement effect of U.S: vs. non-U.S. bank mergers: do they differ?. The Journal of Financial Research, 26(4), 487-500.

Diaz, B.D., Olalla, M.G., Azofra, S.S. (2004). Bank acquisitions and performance: evidence from a panel of European credit entities. Journal of Economics and Business, 56(5), 377-404.

Ellis, P.D. (2006). Market Orientation and performance: A meta-Analysis and Cross-National Comparisons. Journal of Management Studies, 43(5), 1089-1107.

*Ferretti, R. (2000). Le acquisizioni bancarie e la reazione del mercato borsistico: le analisi in Usa, Europa e Italia. Bancaria, 56(10), 26-33.

*Goergen, M., Renneboog, L. (2004). Shareholder Wealth Effects of European Domestic and Crossborder Takeover Bids. European Financial Management, 10(1), 9-45.

Healy, P.M., Palepu, K.G., Ruback, R.S. (1992). Does corporate performance improve after mergers? Journal of Financial Economics, 31(2), 135-175.

Hitt, M., Harrison, J., Ireland, R.D., Best, A. (1998). Attributes of successful and unsuccessful acquisition of U.S. firms. British Journal of Management, 9(2), 91-114.

Hoskisson, R.E., Hitt, M.A., Johnson, R.A., Moesel, D.D. (1993). Construct validity of an objective (entropy) categorical measure of diversification strategy, Strategic Management Journal, 14(3), 215-235. 
Hunter, J.E., Schmidt F.L. (1990). Methods of Meta-Analysis. Newbury Park, CA:Sage.

Jensen, M.C., Ruback, R.S. (1983). The market for corporate control: the scientific evidence. Journal of Financial Economics, 11, 5-50.

King, D.R., Dalton, D.R., Daily, C.M., Covin, J.G. (2004). Meta-analyses of Post-Acquisition performance: indications of unidentified moderators. Strategic Management Journal, 25(2), 187-200.

Larsson, R., Finkelstein, S. (1999). Integrating strategic, organizational and human resource perspective on merger and acquisition: A case survey of synergy realization. Organization Science, 10(1), 1-27.

*Lepetit, L., Patry, S., Rous, P. (2004). Diversification versus specialization: an event study of M\&As in the European banking industry. Applied Financial Economics, 14(9), 663-669.

Lipsey, M.W., Wilson, D.B. (2001). Practical meta-analysis. Thousand Oaks, CA: Sage.

Loughran, T., Vijh A.M. (1997). Do Long-Term Shareholders Benefit From Corporate Acquisitions? Journal of Finance, 52(5), 1765-1790.

Louis, H. (2004). Earnings management and the market performance of acquiring firms. Journal of Financial Economics, 74(1), 121-148.

Magenheim, E.B., Mueller, D.C. (1988). Are Acquiring-Firm Shareholders Better Off after an Acquisition?. In Coffee, J.C., Lowenstein, L. and Rose-Ackerman, S. Knights, Raiders and Targets: The Impact of the Hostile Takeover. Oxford University Press: New York.

Megginson, W.L., Morgan, A., Nail, L. (2004). The determinants of positive long-term performance in strategic mergers: corporate focus and cash. Journal of Banking and Finance, 28(3), 523-552.

Melis, A. (2000). Corporate Governance in Italy. Corporate Governance: An International Review, 8(4), 347-355.

*Mylonidis, N., Kelnikola, I. (2005). Merging activity in the Greek banking system: a financial accounting perspective. South Eastern Europe Journal of Economics, 1, 121-144.

Rau R., Vermaelen, T. (1998). Glamour, value and the post-acquisition performance of acquiring firms. Journal of Financial Economics, 49(2), 223-253.

Resti, A., Galbiati, L. (2004). Competitività e M\&A: le aggregazioni bancarie creano valore? Il punto di vista del mercato. In Bracchi, G., Masciandaro, D. La competitività dell'industria bancaria, Nono rapporto sul sistema finanziario italiano, Fondazione Rosselli, Edibank, Milano. 
*Resti, A., Siciliano, G. (1999). Do bank acquisition increase shareholder's wealth? A comparison between market based and accounting-based performance indicators for some Italian banks, WPS.

Roll, R. (1986). The Hubris Hypothesis of Corporate Takeovers. Journal of Business, 59(2), 198-216.

Rosenthal, R. (1991). Meta-analytic procedures for social research. Newbury Park, CA: Sage.

*Savona, R. (2002). Fusioni e acquisizioni bancarie in Italia, 1989-1997: un'analisi empirica sulla reattività dei prezzi azionari. Bancaria, 1, 31-52.

Schweiger, D.M., Goulet, P.K. (2000). Integrating mergers and acquisitions: and international research review. Advances in Mergers and Acquisition, 1, 61-91.

Shapiro, D.A., Shapiro, D. (1982). Meta-analysis of comparative psychotherapy outcomes studies. Psychological Bulletin, 92(3), 581-604.

*Silva, J.V., Diz, M. (2005). Mergers And Acquisitions In The Portuguese Banking Industry: Is It There A Process Of Value Creation?. EconWPA.

Singh, H., Zollo, M. (2004). Globalization through acquisitions and alliances: An evolutionary perspective. In Gatignon, H., Kimberly, J. The INSEAD-Wharton Alliance on Globalizing: Strategies for building successful global businesses. Cambridge: Cambridge University Press.

Sirower, M.L. (1997). The Synergy Trap: How Companies Lose the Acquisition Game. Free Press: New York.

*Tourani Rad, A., Van Beek, L. (1999). Market Valuation of European Bank Mergers. European Management Journal, 17(5), 532-540.

Walker, M.M. (2000). Corporate Takeovers, Strategic Objectives, and Acquiring-Firm Shareholder Wealth. Financial Management, 29(1), 53-56.

*Well, J. (2006). The wealth effect of banking merger announcements. WPS. 
Table 1. Trend in the number of credit institutions in EU countries

\begin{tabular}{|c|c|c|c|c|c|c|c|c|c|c|}
\hline EU Country & 1990 & 1995 & 1998 & 1999 & 2000 & 2001 & 2002 & 2003 & 2004 & 2005 \\
\hline Austria & 1,210 & 1,041 & 898 & 875 & 848 & 836 & 823 & 896 & 883 & 880 \\
\hline Belgium & 157 & 145 & 123 & 117 & 118 & 112 & 111 & 108 & 104 & 100 \\
\hline Finland & 529 & 381 & 348 & 346 & 341 & 369 & 369 & 366 & 363 & 363 \\
\hline France & 2,027 & 1,469 & 1,226 & 1,159 & 1,099 & 1,050 & 989 & 939 & 897 & 854 \\
\hline Germany & 4,720 & 3,785 & 3,238 & 2,992 & 2,742 & 2,526 & 2,363 & 2,225 & 2,148 & 2,089 \\
\hline Greece & 39 & 53 & 59 & 57 & 57 & 61 & 61 & 59 & 62 & 62 \\
\hline Ireland & 48 & 56 & 78 & 81 & 81 & 88 & 85 & 80 & 80 & 78 \\
\hline Italy & 1,156 & 970 & 934 & 890 & 861 & 843 & 821 & 801 & 787 & 792 \\
\hline Luxembourg & 177 & 220 & 212 & 211 & 202 & 194 & 177 & 169 & 162 & 155 \\
\hline Netherlands & 111 & 102 & 634 & 616 & 586 & 561 & 539 & 481 & 461 & 401 \\
\hline Portugal & 260 & 233 & 227 & 224 & 218 & 212 & 202 & 200 & 197 & 186 \\
\hline Spain & 696 & 506 & 402 & 387 & 368 & 367 & 359 & 348 & 346 & 348 \\
\hline Euro area & 11,130 & 8,961 & 8,379 & 7,955 & 7,521 & 7,219 & 6,899 & 6,672 & 6,490 & 6,308 \\
\hline Denmark & 124 & 122 & 212 & 210 & 210 & 203 & 178 & 203 & 202 & 197 \\
\hline Sweden & 704 & 249 & 148 & 148 & 146 & 149 & 216 & 222 & 212 & 200 \\
\hline United Kingdom & 624 & 564 & 521 & 496 & 491 & 452 & 451 & 426 & 413 & 400 \\
\hline EU & 12,582 & 9,896 & 9,260 & 8,809 & 8,368 & 8,023 & 7,744 & 7,523 & 7,317 & 7,105 \\
\hline
\end{tabular}

Source: ECB 2000, 2006. 
Table 2. Number of domestic (D) and cross-border (C-B) M\&As in EU countries

\begin{tabular}{|c|c|c|c|c|c|c|c|c|c|c|c|c|c|c|c|c|c|c|}
\hline \multirow[t]{2}{*}{ EU Country } & \multicolumn{2}{|c|}{1995} & \multicolumn{2}{|c|}{1998} & \multicolumn{2}{|c|}{1999} & \multicolumn{2}{|c|}{2000} & \multicolumn{2}{|c|}{2001} & \multicolumn{2}{|c|}{2002} & \multicolumn{2}{|c|}{2003} & \multicolumn{2}{|c|}{2004} & \multicolumn{2}{|c|}{2005} \\
\hline & $\mathrm{D}$ & $\mathrm{C}-\mathrm{B}$ & $\mathrm{D}$ & $\mathrm{C}-\mathrm{B}$ & $\mathrm{D}$ & C-B & $\mathrm{D}$ & $\mathrm{C}-\mathrm{B}$ & $\mathrm{D}$ & $\mathrm{C}-\mathrm{B}$ & $\mathrm{D}$ & $\mathrm{C}-\mathrm{B}$ & $\mathrm{D}$ & $\mathrm{C}-\mathrm{B}$ & $\mathrm{D}$ & C-B & $\mathrm{D}$ & $\mathrm{C}-\mathrm{B}$ \\
\hline Austria & 14 & 0 & 37 & 0 & 20 & 4 & 1 & 1 & 2 & 2 & 2 & 0 & 0 & 0 & 2 & 0 & 1 & 1 \\
\hline Belgium & 6 & 0 & 6 & 1 & 6 & 5 & 1 & 0 & 1 & 1 & 1 & 0 & 1 & 0 & 1 & 2 & 5 & 3 \\
\hline Finland & 7 & 2 & 5 & 2 & 2 & 0 & 0 & 0 & 0 & 0 & 1 & 0 & 1 & 0 & 1 & 0 & 1 & 1 \\
\hline France & 60 & 1 & 52 & 1 & 51 & 4 & 3 & 5 & 4 & 2 & 5 & 2 & 8 & 0 & 5 & 0 & 2 & 0 \\
\hline Germany & 100 & 22 & 189 & 13 & 240 & 29 & 2 & 2 & 13 & 3 & 10 & 4 & 13 & 0 & 6 & 1 & 9 & 3 \\
\hline Greece & 0 & 0 & 7 & 2 & 3 & 5 & 3 & 1 & 1 & 0 & 4 & 1 & 1 & 0 & 1 & 1 & 0 & 2 \\
\hline Ireland & 1 & 2 & 2 & 1 & 1 & 1 & 0 & 1 & 0 & 1 & 0 & 1 & 1 & 0 & 0 & 1 & 1 & 1 \\
\hline Italy & 68 & 5 & 52 & 3 & 64 & 2 & 38 & 3 & 15 & 4 & 32 & 7 & 32 & 9 & 22 & 8 & 34 & 6 \\
\hline Luxembourg & 3 & 0 & 9 & 3 & 6 & 4 & 2 & 2 & 4 & 2 & 5 & 2 & 0 & 0 & 1 & 0 & 1 & 2 \\
\hline Netherlands & 2 & 5 & 0 & 3 & 1 & 2 & 0 & 4 & 2 & 1 & 1 & 0 & 2 & 2 & 1 & 1 & 0 & 0 \\
\hline Portugal & 5 & 1 & 1 & 4 & 0 & 2 & 4 & 4 & 2 & 0 & 1 & 1 & 5 & 4 & 1 & 2 & 1 & 1 \\
\hline Spain & 4 & 9 & 5 & 10 & 5 & 12 & 4 & 4 & 1 & 1 & 7 & 1 & 4 & 3 & 4 & 2 & 4 & 1 \\
\hline Euro area & 270 & 47 & 365 & 43 & 399 & 70 & 58 & 27 & 45 & 17 & 69 & 19 & 68 & 18 & 45 & 18 & 59 & 21 \\
\hline Denmark & 2 & 0 & 1 & 0 & 0 & 2 & 0 & 1 & 1 & 1 & 1 & 1 & 0 & 1 & 3 & 0 & 0 & 0 \\
\hline Sweden & 1 & 0 & 1 & 0 & 1 & 6 & 0 & 0 & 1 & 0 & 1 & 0 & 0 & 0 & 1 & 0 & 0 & 0 \\
\hline United & 2 & 4 & 16 & 8 & 14 & 5 & 2 & 0 & 7 & 1 & 1 & 0 & 1 & 0 & 5 & 1 & 5 & 1 \\
\hline$E U$ & 275 & 51 & 383 & 51 & 414 & 83 & 60 & 28 & 54 & 19 & 72 & 20 & 69 & 19 & 54 & 19 & 64 & 22 \\
\hline
\end{tabular}

Source: ECB 2000, 2006.

Table 3. Summary of the meta-analysis results for M\&A value creation

\begin{tabular}{lccccccccc}
\hline \hline Meta-analysis & Sample size & N. of Observations & Observed $\boldsymbol{C}$ & Corrected $\boldsymbol{r}$ & $\boldsymbol{S E} \boldsymbol{r}$ & $\mathbf{9 5 \%} \boldsymbol{C I}$ & $\boldsymbol{Q}(\boldsymbol{S}-1)$ \\
\hline Target & 4,170 & 67 & 0.009 & 0.570 & 0.000 & 0.570 & 0.571 & 586.3 \\
Buyer & 10,498 & 83 & 0.000 & 0.045 & 0.000 & 0.045 & 0.045 & 149.9 \\
Combined & 2,339 & 41 & 0.006 & 0.402 & 0.000 & 0.402 & 0.403 & 170.7 \\
Total & 17,007 & 191 & & & & & & & \\
\hline
\end{tabular}


Table 4. Mean effect sizes and confidence intervals for moderator sub-groups

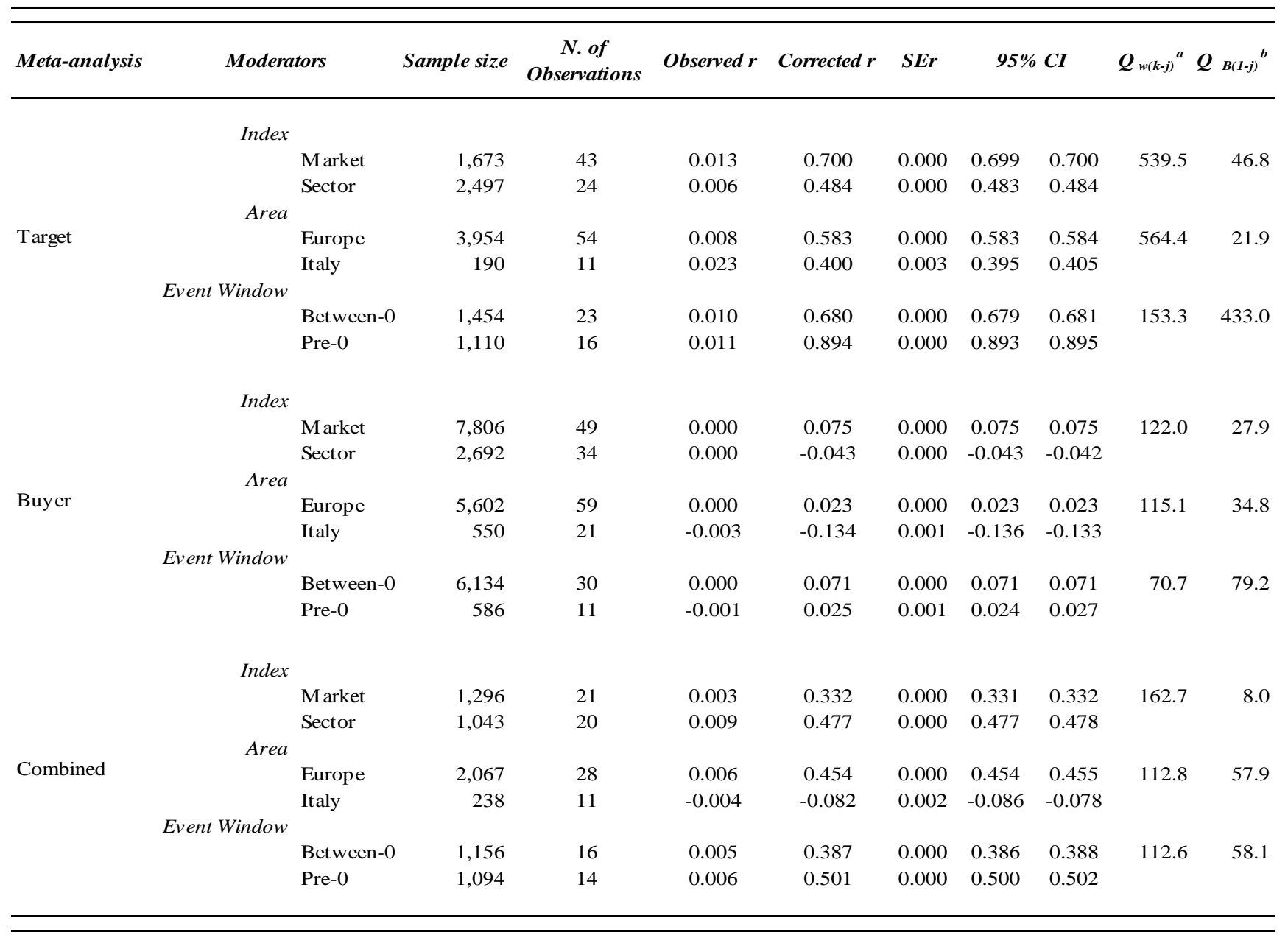

Notes:

${ }^{a} Q_{w(k-j)}$ refers to the residual pooled within-groups share of the variance with $(k-j)$ degrees of freedom, where $k$ and $j$ denote the number of effect sizes and categories respectively.

${ }^{\mathrm{b}} \mathrm{Q}_{\mathrm{B}(1-\mathrm{j})}$ refers to the residual variance between-groups with $(1-\mathrm{j})$ degrees of freedom. 